\title{
UJI AKTIVITAS LARVASIDA EKSTRAK TERPURIFIKASI DAGING BUAH MIMBA (Azadirachta indica A. Juss.) ASAL PULAU LOMBOK TERHADAP Aedes aegypti
}

\author{
Selpida Handayani, Aktsar Roskiana A, Umi K R Karim
}

Fakultas Farmasi Universitas Muslim Indonesia

Email : shelpida@ymail.com

\begin{abstract}
Neem (Azadirachta indica A.Juss.) Is a plant that has medicinal benefits as malaria, antitukak stomach and is also can used as natural insecticides, fungicides, larvicides and antifertility. This Research aims to know the mortality rate of larvae of Aedes aegypti with $L_{5} C_{50}$ values indicated. Neem fruit plucked from a tree lombok island.neem. Extracts obtained by maceration solvent with the masceration methanol. Retrieved rendamen extract as much as $25,17 \%$, then purified with $n$ hexane solvent. Larvasida test used 180 larvae of Aedes aegypti first instar III. Test solutions were made in 4 concentration, positive control using powder Abate ${ }^{\circledR}$ (Themephos), and a negative control. Observations were made after 24 hours of treatment . Aedes aegypti larval mortality analyzed with probid analysis to know $L C_{50}$ and obtained phytochemical components contained in the methanol extracts were saponins and tannins. $L C_{50}$ obtained from the methanol extract of neem fruit flesh is $1817,18 \pm 1,075 \mu \mathrm{g} / \mathrm{ml}$. This shows the methanol extract of neem fruit flesh (Azadirachta indica A.Juss.) Does not have the effect toxicity against larvae of Aedes aegypti indicated by $L C_{50}>1000$ ppm.
\end{abstract}

Keywords: Flesh neem, Azadirachta indica A. Juss., Aedes aegypti, $\mathrm{LC}_{50}$.

\section{PENDAHULUAN}

Indonesia dikenal dengan keragaman suku bangsa dan keragaman bahasa. Adat istiadat dan kebiasaan tiap daerah sangatlah berbeda, hal tersebut dipengaruhi oleh nenek moyang masing-masing daerah yang memiliki kebiasaan tersendiri, sehingga terdapat beragam cara melakukan aktifitas keseharian di lingkungan masing-masing. Seperti halnya dalam memelihara kesehatan, setiap daerah memilki cara atau metode khusus dalam pengobatan seperti penggunaan beberapa tumbuhan tertentu dan membuatnya menjadi sebuah ramuan yang dapat berkasiat penyembuh berbagai penyakit.

Saat ini tanaman obat menjadi salah satu alternatife obat yang dipilih oleh masyarakat luas. Hal ini karena tanaman obat tidak mempunyai efek samping yang besar bila dibandingkan 
Uji Aktivitas Larvasida Ekstrak Terpurifikasi Daging Buah Mimba Asal Pulau Lombok Terhadap Aedes Aegypti

dengan obat modern yang terbuat dari bahan kimia sintesis. Selain itu, tanaman obat pun semakin popular dengan makin meluasnya informasi dan penanganan medis secara tradisional yang ditayangkan di televisi sehingga membuat masyarakat luas semakin tertarik untuk mencoba dan memanfaatkan tanaman obat (Raina, 2011).

Salah satu pulau yang memiliki keanekaragaman penggunaan tumbuhan obat adalah pulau Lombok. Menurut data dari Badan Pusat Statistik wilayah Nusa Tenggara Barat tahun 2010, pulau Lombok merupakan pulau yang memiliki luas $4.738,65 \mathrm{~km}^{2}$ atau $23,51 \%$ dari wilayah Provinsi Nusa tenggara Barat dan memiliki hutan seluas $163.061,41$ ha dimana beberapa bagiannya merupakan hutan lindung yang terdapat begitu banyak tanaman buah-buahan, MPTS (Multi Purpose Tree Cropp Spesies) dan tanaman pangan (IPB, 2011).

Salah satu tanaman yang terdapat di pulau Lombok yang dapat berkasiat sebagai obat adalah tumbuhan kayu Mimba (Azadiractha indica A. Juss) dimana bahan aktif biji mimba bermanfaat untuk mengusir serangga pengganggu, mencegah hama pemakan tanaman, menghalau larva dan serangga dewasa, mencegah terjadinya pergantian kulit larva, menurunkan produksi telor pada serangga betina, dan mencegah serangga betina meletakan telor. Senyawa-senyawa yang diyakini sebagai bahan aktif insektisida adalah nimbin (nimbinen), nimbidin, meliantriol, azadirachtin dan salanin yang merupakan senyawa kimia dari kelompok terpena. Ekstrak yang dibuat dari biji mimba dapat digunakan untuk mengendalikan berbagai jenis hama seperti Helopeltis sp., ulat jengkal, Aphis sp., Nilarvata sp., dan Sitophilus sp. (Wiryowidagdo dalam suirta 2007). Dari penelitian sebelumnya dengan menggunakan biji Mimba (Azadirachta indica A. Juss) sebagai larvasida di peroleh salah satu Fraksi yang di ujikan memiliki nilai $L_{50}=143,97$ ppm (Suirta, 2007).

Ada beberapa cara untuk mengusir nyamuk, salah satunya dengan menggunakan tanaman obat, seperti zodia (Evodia suaveolens), serai wangi (Cymbopogon nardus), lavender (Lavandula latifolia), geranium (Geranium homeanum), nilam (Pogostemon cablin), dan mimba (Azadirachta indica) (Litbang, 2008).

Salah satu penyakit yang selalu datang setiap musim hujan adalah penyakit demam berdarah. Penyakit ini 
Uji Aktivitas Larvasida Ekstrak Terpurifikasi Daging Buah Mimba Asal Pulau Lombok Terhadap Aedes Aegypti

banyak menyerang bayi, anak-anak bahkan tidak sedikit orang dewasa. Penyakit ini terkadang kurang di ketahui masyarakat sehingga terkadang terjadi keterlambatan penanganan pada pasien. $\mathrm{Di}$ Indonesia, penyakit ini muncul diseluruh provinsi dan meningkat kejadiannya pada musim hujan. Pada tahun 2004, penyakit ini menjadi berita utama di hampir semua media cetak nasional, dan banyak yang berakhir dengan kematian (Hastuti, 2008).

Pohon mimba banyak di temui di pulau Lombok, biasanya pohon ini di tanam di pinggir jalan sebagai peneduh jalanan, namun masih belum banyak orang yang mengetahui khasiat dari pohon tersebut. Di kota Bima daging buah mimba biasa dikonsumsi karena rasnya yang manis begitu pula dengan hewan pemakan buah lainnya juga biasa mengkonsumsi buah ini setelah matang dan membuang bijinya yang cenderung pahit.

Daging buahnya berasa manis dan menyelimuti biji. Karena rasanya yang manis itulah, daging buah sering dimakan burung atau kelelawar. Namun, sampai saat ini, daging buah mimba belum ada yang memanfaatkannya, meskipun tidak beracun (Sukrasno, 2003).
Berdasarkan hal tersebut, untuk memanfaatkan daging buah mimba yang belum diketahui manfaatnya maka dilakukan penelitian uji aktivitas larvasida daging buah mimba ini yang sebelumnya telah dilakukan penelitian serupa dengan menggunakan biji mimba.

\section{METODE PENELITIAN}

\section{Bahan}

Bahan-bahan yang digunakan pada penelitian ini adalah Abate $^{\circledR}$ (Themepos), air bersih, Aluminium foil, Biakan larva nyamuk demam berdarah (Aedes Aegypty), Metanol, n-Hexan, Daging buah Mimba (Azadiractha Indica A. Juss), Kertas saring, Tissu.

\section{Peralatan}

Alat-alat yang digunakan adalah batang pengaduk, cawan porselin, Chamber, Corong, Gelas kimia, Gelas ukur, Labu Erlenmeyer, Mikro pipet, neraca analitik, pipa kapiler, pipet tetes, pipet skala, sendok tanduk,sonikator, Timbangan ohaus, Vial.

\section{Prosedur kerja}

Sampel Daging buah Mimba (Azadiractha Indica A.Juss) yang telah dikeringkan ditimbang sebanyak 340 gram kemudian dimasukkan kedalam wadah maserasi. Lalu ditambahkan 
Uji Aktivitas Larvasida Ekstrak Terpurifikasi Daging Buah Mimba Asal Pulau Lombok Terhadap Aedes Aegypti

dengan metanol $500 \mathrm{ml}$ hingga simplisia tersebut terendam, ditutup dan dibiarkan selama 3-5 hari dengan pengadukan sesekali. Setelah disaring dan ampasnya direndam lagi dengan cairan penyari yang baru, hal ini dilakukan sampai cairan penyari yang diperoleh berwarna bening. Hasil penyarian kemudian diuapkan dengan menggunakan Hair dryer hingga diperoleh ekstrak kental.

Pemurnian ekstrak daging buah mimba dengan menggunakan pelarut n-hexan bertujuan untuk memurnikan ekstrak dari senyawa lemak yang banyak terdapat pada buah. Ekstrak Metanol kental daging buah mimba (Azadiractha indica. A.Juss) di timbang sebanyak 20 gram kemudian di larutkan dengan $n$-hexan $50 \mathrm{ml}$ kemudian dilakukan proses pemisahan senyawa pengotor dengan alat sonikator. n-heksan digunakan untuk menarik lemak yang banyak terdapat pada buah mimba (Azadiractha indica. A.Juss) kemudian dilakukan pemisahan pelarut $n$-heksan yang berwarna keruh kedalam wadah kemudian di masukkan lagi n-heksan yang baru sebanyak $50 \mathrm{ml}$ dan dilakukan sonikasi kembali hingga $n$ heksan yang di tambahkantidak berwarna keruh atau benar-benar jernih.
Ekstrak ditimbang 0,1 gram. Kemudian dimasukkan kedalam gelas kimia $50 \mathrm{~mL}$. kemudian di larutkan dengan $10 \mathrm{ml}$ methanol proanalisis, kemudian di pipet $5 \mu \mathrm{L}, 50 \mu \mathrm{L}, 500 \mu \mathrm{L}$ dan $5000 \mu \mathrm{L}$ kedalam wadah vial dengan variasi konsentrasi berturutturut 10 ppm, 100 ppm, 1000 ppm, dan 10.000 ppm. Kemudian dicukupkan volumenya sampai $5 \mathrm{ml}$ kemudian diuapkan selama 24 jam. Sedangkan untuk ontrol positif Serbuk abate di timbang sebanyak 0,02 gram dan dilarutkan dengan air $5 \mathrm{~mL}$.

Dimasukkan $2 \mathrm{~mL}$ air, $50 \mu \mathrm{L}$ dimetilsulfoksida, 10 larva nyamuk Aedes aegypti kedalam vial kemudian ditambahkan air hingga volumenya mencapai $5 \mathrm{~mL}$. Pengamatan dilakukan setelah 24 jam terhadap kematian larva nyamuk. Setiap konsentrasi, control positif dan ontrol negative dilakukan dengan tiga kali replikasi. Bila $\mathrm{LC}_{50}$ dibawah 1000 $\mu \mathrm{g} / \mathrm{mL}$ dinyatakan bersifat toksik dan diatas $1000 \mu \mathrm{g} / \mathrm{mL}$ dinyatakan tidak toksik.

Metode larvasida digunakan sebagai pengujian aktivitas larvasida terhadap nyamuk Aedes aegypti Sebanyak 10 ekor larva nyamuk Aedes aegypti instar ke III dipindahkan dari wadah penampung kedalam gelas piala yang berisi ekstrak (sesuai 
Uji Aktivitas Larvasida Ekstrak Terpurifikasi Daging Buah Mimba Asal Pulau Lombok Terhadap Aedes Aegypti

konsentrasi), abate dan control (Antonius, 2010).

\section{HASIL DAN PEMBAHASAN}

Buah mimba memiliki bentuk bulat lonjong seperti melinjo dengan ukuran maksimum $2 \mathrm{~cm}$. buah yang matang berwarna kuning atau hijau kekuningan. Daging buahnya berasa manis dan menyelimuti biji. Karena rasanya yang manis itulah, daging buah sering dimakan burung atau kelelawar. Namun sampai saat ini, daging buah mimba belum ada yang memanfaatkannya, meskipun tidak beracun (Sukrasno,2003).

Pada penelitian ini digunakan buah mimba utuh sebanyak 3 kilogram dan diperoleh daging buah mimba kering sebanyak 340 gram yang telah dihaluskan kemudian di ekstraksi dengan metode maserasi. Metode ini dipilih karena mudah dilakukan dan selain itu dikahwatirkan senyawa yang di kandung daging buah mimba tidak tahan panas. Daging buah mimba dimaserasi ini dengan pelarut metanol yang merupakan pelarut yang memiliki kepolaran yang tinggi. Proses ekstraksi dengan metode Maserasi dengan menggunakan pelarut metanol yang bersifat polar untuk menarik senyawa-senyawa kimia yang secara keseluruhan. Hal ini dilakukan karena

belum diketahuinya komponenkomponen kimia yang memiliki aktifitas yang besar terhadap larva nyamuk Aedes aegipty sedangkan untuk proses purifikasinya atau pemurnian ekstrak dari senyawa yang tidak berguna yaitu dengan menggunakan pelarut $\mathrm{n}$-heksan yang merupakan pelarut yang memiliki kepolaran rendah, kemudian ekstrak tersebut dapat dkatakan bebas dari senyawasenyawa pengganggu seperti lemak yang umunya banyak terdapat pada daging buah sehingga ekstrak yang diperoleh untuk diujikan nantinya termurikan dari senyawa minyak dan pengotor-pengotor lainnya.

Menurut Agoes

(2007)

Ekstrak tanaman dapat dikelompokkan dalam 2 kelompok utama, yaitu ekstrak total dan ekstrak dimurnikan. Terminologi total atau ekstrak tadisional menunjukkan ekstrak mengandung semua bahan terekstraksi yang diperoleh dengan penarikan menggunakan suatu pelarut, lazimnya air atau cairan hidroalkohol. Ekstrak yang dimurnikan berarti ekstrak tidak mengandung zatzat yang tidak diperlukan dan tidak memepengaruhi proses penghilangan zat inert dengan berbagai cara (menghilangkan lemak atau diawetkan melalui resin absorpsi) sesudah 
Uji Aktivitas Larvasida Ekstrak Terpurifikasi Daging Buah Mimba Asal Pulau Lombok Terhadap Aedes Aegypti

ekstraksi primer. Terminology zat inert digunakan terutama untuk resin, lemak dan gula-gula. Semua bahan yang merupakan penghalang / penghambat utama dalam pembuatan sediaan farmasi. Ekstrak adalah bahan baku yang mengandung beraneka ragam bahan aktif tetapi dalam jumlah kecil. Sebagian besar merupakan bahanbahan sekunder (garam organic dan anorganik, gula-gula polisakharida, dan sebagainya) yang dapat mempengaruhi teknologi pembuatan dan stabilitas sediaan farmasi (Agoes, 2007). Pada penelitian sebelumnya dilakukan pengujian dengan serbuk biji mimba 1000 gram diekstraksi dengan cara maserasi menggunakan $\pm 20 \mathrm{~L}$ etanol teknis sampai semua komponen habis terekstraksi (Suirta,2007).

Dilakukan maserasi dengan pelarut methanol teknis, rendamen tersebut disimpan selama 3 hari, hal ini dimaksudkan agar proses penarikan senyawa dari ekstrak tersebut berlangsung sempurna dan proses maserasi telah tercapai yang ditandai dengan filtrate yang berwarna pucat. Saat proses maserasi berlangsung di lakukan beberapa kali pengadukan agar proses maserasi dapat berlangsung cepat. Ekstrak yang di peroleh dari maserasi ini sekitar 85,6 gram ekstrak kental dengan menggunakan $2 \mathrm{~L}$ pelarut methanol teknis. Dari ekstrak yang diperoleh tersebut dapat dilihat total rendamen yang diperoleh yaitu $25,17 \%$ (b/b) dan pada ekstrak terpurifikasi diperoleh $91 \%$ rendamen ekstrak dari 20 gram ekstrak yang di purifikasi.

Setelah proses ekstraksi, dilakukan pengujian kandungan metabolit sekunder daging buah mimba (Azadiractha indica A.Juss.) dengan menggunakan reagen kimia dan diperoleh ekstrak methanol buah mimba (Azadiractha indica A.Juss.) positif mengandung tannin dan saponin. Sedangkan pada penelitian sebelumnya dengan mengguankan biji mimba (Azadiractha indica A.Juss.) diperoleh senyawa metabolit sekunder golongan triterpenoid, flavonoid dan alkaloid (Suirta,2007).

Pengujian selanjutnya yaitu uji toksisitas ekstrak metanol daging buah mimba (Azadiractha indica A. Juss.) dalam konsentrasi 10,100, 1000, $10.000 \mu \mathrm{g} / \mathrm{ml}$ dengan control positif yaitu Abate $^{\circledR} 10 \mu \mathrm{g} / \mathrm{ml}$ dan control negatife berupa air, diujikan terhadap larva nyamuk Aedes aegipty. Pengamatan dilakukan selama 24 jam setelah perlakuan dengan parameter kematian Larva nyamuk. Aktivitas 
Uji Aktivitas Larvasida Ekstrak Terpurifikasi Daging Buah Mimba Asal Pulau Lombok Terhadap Aedes Aegypti

larvasida yang diamati yaitu selama 24 jam. Perhitungan waktu dimulai setelah pemasukan larva kedalam gelas piala (Antonius, 2010).

Pengamatan alur hidup yaitu larva uji diberikan ekstrak mampu bertahan hidup pada jangka waktu tertentu namun tidak dapat mencapai tahap selanjutnya. Efek kematian dimaksud yaitu larva uji mengalami mortilitas akibat adanya aktivitas ekstrak larvasida yang diberikan (Antonius, 2010).

Dari penelitian yang dilakukan diperoleh LC $_{50}$ (Lethal Concentration) adalah total kematian yang diperlihatkan suatu senyawa uji pada $50 \%$ hewan uji yaitu sebesar $1.817,18$ $\pm 1,075 \mu \mathrm{g} / \mathrm{mL}$. Diamana suatu senyawa dikatakan memiliki aktiviats toksisitas akut pada $\mathrm{LC}_{50}$ kurang dari $1000 \mathrm{ppm}(\mu \mathrm{g} / \mathrm{mL})$. Perhitungan ini berdasarkan analisis probid dan standar deviasi. Dari hasil analisis tersebut ekstrakdaging buah mimba (Azadiractha indica A. Juss.) tidak memiliki potensi toksisitas akut sebagai larvasida dengan range lebih dari $1000 \mathrm{ppm}(\mu \mathrm{g} / \mathrm{mL})$.

Dari data yang diperoleh daging buah mimba (Azadiractha indica A. Juss.) memilki potensi yang rendah sebagai larvasida, hal ini di karenakan senyawa kimia yang terkandung pada daging buah mimba (Azadiractha indica A. Juss.) sebagai larvasida belum dalam bentuk senyawa tunggal.

\section{KESIMPULAN DAN SARAN}

\section{Kesimpulan}

Berdasarkan hasil penelitian dapat disimpulkan bahwa ekstrak terpurifikasi daging buah mimba (Azadiractha indica A. Juss.) tidak memiliki efek toksisitas dengan nilai LC $_{50}$ sebesar $1817,18 \pm 1,075 \mu \mathrm{g} / \mathrm{ml}$.

\section{DAFTAR PUSTAKA}

Agoes, goeswin. 2007. Teknologi bahan alam.Penerbit ITB: Bandung

Amanda, H. 2013. Isolasi Dan Karakterisasi Senyawa Fenolik Dari Tumbuhan Patikan Cina (Euphorbia thymifolia Linn), (online), (http:kipunja-ok.com, diakses 09 maret 2013)

Amanda, V. 2005. Uji aktifitas antimikroba ekstrak eter daun mimba (Azadirctha indica A.Juss) secara KLT bioautografi terhadap bakteri Staphylococcus aureus dan Pseudomonas aeruginosa.(Skripsi),

$\begin{array}{lr}\text { Fakultas } & \text { Farmasi } \\ \text { Universitas } & \text { Muslim } \\ \text { Indonesia.Makassar } & \end{array}$

Colegate, S.M.1993. Bioactive Natural Product. CRC Press: London. 
Uji Aktivitas Larvasida Ekstrak Terpurifikasi Daging Buah Mimba Asal Pulau Lombok Terhadap Aedes Aegypti

Direktorat Jendral Pengawasan Obat dan Makanan.1989. Materi medika Indonesia (vol.5). Departemen Kesehatan Republik Indoneisa, Jakarta.

Ginanjar, Genis. 2007. Apa yang dokter adnda katakana tentang Demam berdarah. Mizan: Yogyakarta

Hasyimi,M. 2005. Pengaruh Themepos terhadap perolehan Telur nyamuk Aedes aegypti (L) di cipinang muara Jakarta,(online), (http:journal.ipb.ac.id, diakses 09 maret 2013 )

Institute Pertanian Bogor. 2011. Kondisi umum Pulau Lombok.(online), (http://repository.ipb.ac.id diakses 09 maret 2013).

I W.Suirta. 2007. Isolasi dan identifikasi senyawa aktif larvasida dari biji mimba (Azadiractha Indica A.Juss) terhadap larva nyamuk demam berdarah (Aedes aegypti), (online),( http://ojs.unud.ac.id, diakses 09 maret 2013).

Khoirun, nisa'. 2006. Kinetika penghambatan oleh ekstrak biji mimba (Azadiractha Indica A.Juss) pada pertumbuhan jamur Alternaria porii penyebab penyakit tanaman bawang merah, (online),( http://elib.pdii.lipi.go.id, diakses 09 maret 2013).

Machfoedz, ircham.2008. Menjaga Kesehatan Rumah dari berbagai

Fitramaya: Yogyakarta.

Marlina. 2005. Skrining Fitokimia dan Analisis kromatografi lapis tipis komponen kimia buah labu siam (Sechium edule Jacq. swatz) dalam ekstrak etanol. Jurusan biologi FMIPA UNS.Biofarmasi: Surakarta, (online),( http:eprints.uns.ac.id, diaskses 09 maret 2013).

Meyer Bn.1982. Brine Shrimp Convinent General Bioassy for Active Plan Constituents.Planta Medica.

Mursyidi, A. 1985.Statistik Farmasi dan bilogi cetakan .I.Ghalia indonesia

Nadesul, Hendrawan.2007. Cara Mudah Mengalahkan Demam berdarah. PT.kompas media Nusantara : Jakarta

Raina. 2011. Ensiklopedi Tanaman Obat Untuk kesehatan.Absolut: Jakarta

Sukrasno, dan tim lentera.2007. Mimba tanaman obat multifungsi. Jakarta: PT.Agro Media Pustaka

Tapan, eric. 2004. Dokter internet Flu, HFMD, Diare pada Pelancong, malaria, $D B D$, Tifus (Online)(http://makassarlib.ne $\mathrm{t}$, diakses 09 Maret 2013).

Winarno. F.G., 2008. Kimia Pangan dan Gizi. Bogor: M-Brio Press. 